\title{
Applying EDAS Method to Solve Air Traffic Problems
}

\author{
Michaël K. KIKOMBA \\ Institut Supérieur de Techniques Appliquées, ISTA/Kasangulu. RD Congo. \\ Rostin M. MABELA
}

Département de Mathématiquesetinformatique, Université de Kinshasa, RD Congo.

\section{Donatien I. NTANTU}

Facultés des Sciences.

Université Pédagogique Nationale

\begin{abstract}
Regular increase in the request for traffic in Democratic Republic of Congo generates problems of network saturation involving aircraft collision risk and this under the responsibility of the air controllers. Currently, the air controllers workload is the principal factor of the sectorization. Thus, two major problems arise:How minimize traveling time in the sector? How maximize covered distance?These two objectives are contradictory and related to the controller's responsibility. Interest of this study relates to this simultaneous optimization. Thus, it is important to have an assignment which requires two controllers per sector and which generates various sets of efficient solutions thanks to the EDAS method.
\end{abstract}

Keywords: Elimination of Dominated Acceptable Solutions Method, Simultaneous Optimization, Multiobjective Assignment Problem, Sectorization.

\section{INTRODUCTION}

Optimization, being the searching for the most favorable solution to a decisional problem that fulfills one or more conditions called constraints, is known as combinatory when the used decision variables are binary. It is also described as discrete combinatory optimization owing to the fact that its decision variables are picked in a subset $\{0,1\} \subset \mathbb{N}$.

Among nine Combinatory Optimization Problems appears the assignment problem. In case the mono-objective one, one knows that this problem belongs to class $\mathrm{P}$ problems, and is one of the easiest combinatory optimization problems. Indeed, it is not restrictive to solve its linear relaxation since it checks the property of total unimodality.

On the other hand, taking into account of several objectives in the assignment problem and presence of the discrete variables generate a new surprising difficulty. This difficulty is still for the sectorization problem with several criteria.

Nevertheless, let us announce that for more than four decades, another manner of looking at the problems appeared allowing a better representation of reality. The innovation consists in modelling and optimizing simultaneously several conflicting objectives. Thus, the researcher is either confronted with the search for the optimal solution but with the consequences of a decision with an aim of working out decision-making aid procedures.

The interest of this subject results to the fact that combinatory optimization is an efficient tool for solving management and decision problems. Thus, it empowers modeling control-related loads by building air traffic assignments.

Throughout this study, we make easy the resolution of assignment and sectorization problems of air traffic while providing efficient solutions approximate to this class of the problems. A characterization without scalarizing function that allows to build various assignments and to find as 
well the supported efficient solutions as the unsupported ones; that is to say a manner to find the set of all efficient solutions by the EDAS (Elimination of Dominated Acceptable Solutions) method.

\section{EDAS METHOD: DESCRIPTION}

\subsection{Operational approaches}

Henceforth, we regard criteria as assignment costs. Thus, a solution is as much better than the performance than it realizes on its criteria is minimal (when $c_{i}(\mathrm{~A})<c_{i}\left(\mathrm{a}^{\prime}\right)$ for both solutions a, a' $\in A^{2}$. We consider that a carries out a better performance on $i$ than $\left.\mathrm{a}^{\prime}\right)$. This operation is not restrictive because maximization of a profit can be easily reformulated like the minimization of cost [1].

\subsection{Group Decision Problems}

Problems of group decision are the ones in which the point of view of several individuals (called air controllers in multi-agents systems) is taken into account. Most important problems in this case are the equitable optimization which consists in determining judicious solution for all of the controllers. A solution $a \in A$ is then evaluated according to the point of view of $m$ controllers, which we can represent by the vector $\mathrm{c}(\mathrm{a})=\left(c_{1}(a) \ldots c_{m}(a)\right)$ such that $(a)$ is the value of the solution $a$ for controller $i$. Notice that in this context, the criteria (point of view of those controllers) are commensurable since the taken into account aspect does not change according to the controller, but only its value can differ according to assignment of the latter in sectors.

If we consider the assignment problem of controllers in sectors, the execution time of a task depends on the controller who carries it out, which we represent by a vector of execution times according to competences of the controller [1, 2, 3].

\subsection{Representing in Multicriteria Space}

Definition 2.1 (Multicriteria space).One calls multicriteria space, the space $X_{A} \subseteq \mathbb{R}^{m}$ such that $X_{A}=\left\{x \in \mathbb{R}^{m} / \forall i \in\{1, \ldots, m\}, x_{i}=c_{i}(a), a \in A\right\}$.

To each realizable solution $a \in A$ corresponds a vector $x \in X_{A}$ which is image of $a$ in the criteria space.

Definition 2.2. (Elimination Reference mark of the dominated acceptable solutions). One calls elimination reference mark of the dominated acceptable solutions of a solution $a$, an orthonormed reference mark of origin $O(0,0)$ where the axes of the coordinates are objectives to be optimized.

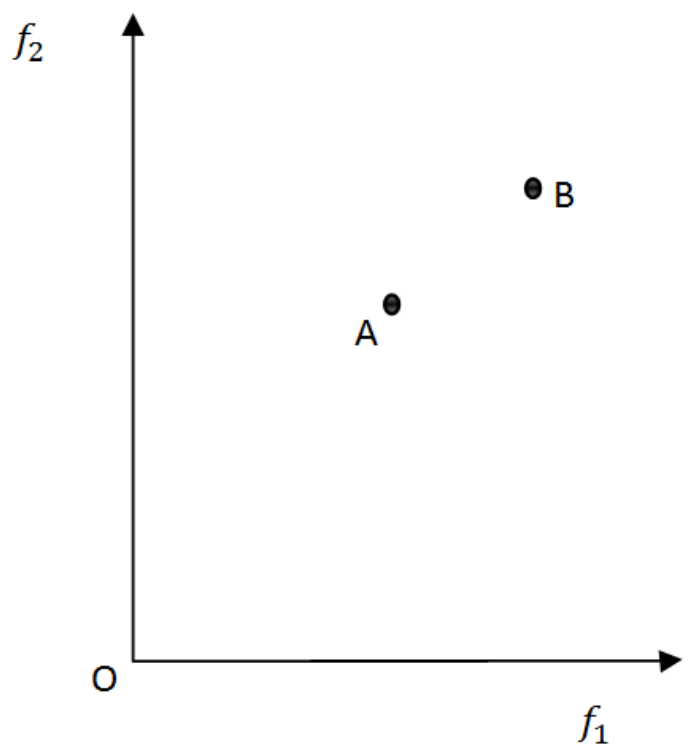

Figure 1. Elimination Reference mark of the dominated acceptable solutions

$f_{1}$ and $f_{2}$ are objectives to be optimized. Thus $\mathrm{A}$ is efficient than $\mathrm{B}$ according to both objectives to be minimized.

To solve a multicriteria problem of assignment by the EDAS (Elimination of Dominated Acceptable Solutions) method, one proceeds as follows: 
1. Determine the cloud of the points by allotting values to each objective;

2. Represent these points in the plan $f_{1}, f_{2}$;

3. Present in a table comparisons between various solutions;

4. Seek for non-dominated solutions;

5. Leave from the table the set of the non-dominated points:

6. Establish a classification of solutions according to the domination ranking.

\subsection{Description of the Algorithm}

\section{INPUT}

$D$ : Set of Acceptable solution for problem $\mathrm{P}$

$$
O: F(O)=\left(f_{i}(a), i=1, \ldots, m, a \in D\right.
$$

\section{OUTPUT}

$E(P)$ : Set of efficient solutions for problem $\mathrm{P}$

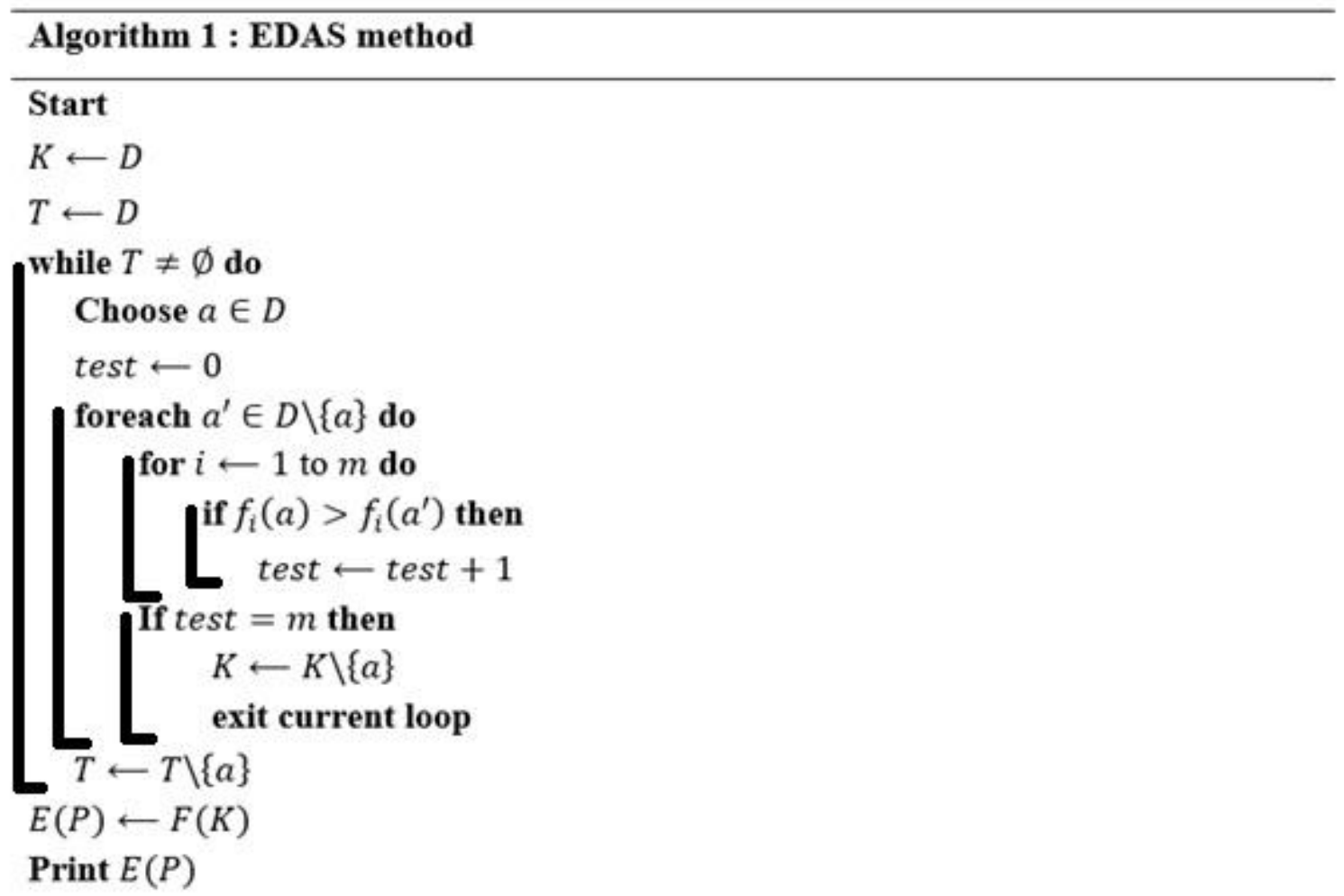

\subsection{Complexity}

Outer loop: $\mathrm{n}$ iterations

First inner loop: $\mathrm{n}-1$ iterations at worst of the cases

Secondinner loop: $\mathrm{m}$ iterations

Complexity at worst of the cases is worth: $\mathcal{O}(n *(n-1) * m)=\mathcal{O}\left(n^{2}\right)$

\subsection{Bases and conventions of the method}

Except the above mentioned bases, one agrees oneself as follows:

Comparing two solutions A and B, results in a couple, in the intersection of row A and column B. This couple consists of three symbols, respectively associated the objectives $f_{1}$ and $f_{2}$; each one of these symbols can take three values:,+- or $=$ according to whether $\mathrm{A}$ is better, less good or of the same level as B with regard to objective this symbol is associated to. 
One seeks to minimize $f_{1}$ and $f_{2}$.

Thus a point $\mathrm{A}$ is better than a point $\mathrm{B}$ vis-à-vis the objective $f_{1}$ if $f_{1}(\mathrm{~A})$ is smaller than $f_{1}(\mathrm{~B})$; a point $\mathrm{A}$ is better than a point $\mathrm{B}$ vis-à-vis the objective $f_{2}$ if $f_{2}(\mathrm{~A})$ is smaller than $f_{2}(\mathrm{~B})$.

Nota :

When the problem comprises two criteria, one can graphically represent the set of solutions in the space of criteria by a set of points in a reference mark whose $\mathrm{x}$-axis is the first criterion and the $\mathrm{y}$-axis the second.

\section{APPLYING EDAS METHOD}

In order to regularize the situation of air traffic, a company of aviation which has its planes and organs in charge of control of the airspace affect controlling agents in sectors at the end of the existing axial network. In front of a situation, these agents do not react in the same way in terms of coordination responsibility and do not have all same competences, same experience and the same contract of employment. The weights granted to the assignment of a controller $i$ with the sector $j$ are given by the matrix E, F and the levels of incompetence corresponding to the loads by the matrices G, H [2].

Table 1. Matrix E: Cost of origin assignment

\begin{tabular}{|c|c|c|c|}
\hline & $S_{1}$ & $S_{2}$ & $S_{3}$ \\
\hline$C_{1}$ & 6 & 4 & 1 \\
\hline$C_{2}$ & 7 & 2 & 3 \\
\hline$C_{3}$ & 1 & 8 & 4 \\
\hline
\end{tabular}

Table 2. Matrix F: Cost of destination assignment

\begin{tabular}{|c|c|c|c|}
\hline & $S_{1}$ & $S_{2}$ & $S_{3}$ \\
\hline$C_{1}{ }^{\prime}$ & 6 & 3 & 2 \\
\hline$C_{2} C_{3}$ & 5 & 1 & 3 \\
\hline & 2 & 7 & 4 \\
\hline
\end{tabular}

Table 3. Matrix G: Levels of origin incompetence

\begin{tabular}{|c|c|c|c|}
\hline & $S_{1}$ & $S_{2}$ & $S_{3}$ \\
\hline$C_{1}$ & 3 & 1 & 3 \\
\hline$C_{2}$ & 2 & 2 & 2 \\
\hline$C_{3}$ & 1 & 3 & 4 \\
\hline
\end{tabular}

Table 4. Matrix H: Levels of destination incompetence

\begin{tabular}{|c|c|c|c|}
\hline & $S_{1}$ & $S_{2}$ & $S_{3}$ \\
\hline$C_{1}{ }^{\prime}$ & 2 & 4 & 1 \\
\hline$C_{2}{ }^{\prime}$ & 1 & 2 & 3 \\
\hline$C_{3}$ & 2 & 1 & 1 \\
\hline
\end{tabular}

\subsection{Solving the Problem}

It is about a problem of simultaneous two objectives minimization: the traveling time in the sector and the number of sectors.

Before installing matrix I of cloud, let us start by adding costs of origin-destination assignment and the levels of incompetence in order to obtain two new matrices $\mathrm{J}$ and $\mathrm{K}$ (respectively assignment costs and levels of incompetence) and to amalgamate both to have I.

Table 5. Matrix I of points cloud (1)

\begin{tabular}{|c|c|c|c|}
\hline & $S_{1}$ & $S_{2}$ & $S_{3}$ \\
\hline$C_{1}{ }^{\prime}$ & $(12,5)$ & $(7,5)$ & $(3,4)$ \\
\hline$C_{2}{ }^{\prime}$ & $(12,3)$ & $(3,4)$ & $(6,5)$ \\
\hline$C_{3}$ & $(3,3)$ & $(15,4)$ & $(8,5)$ \\
\hline
\end{tabular}




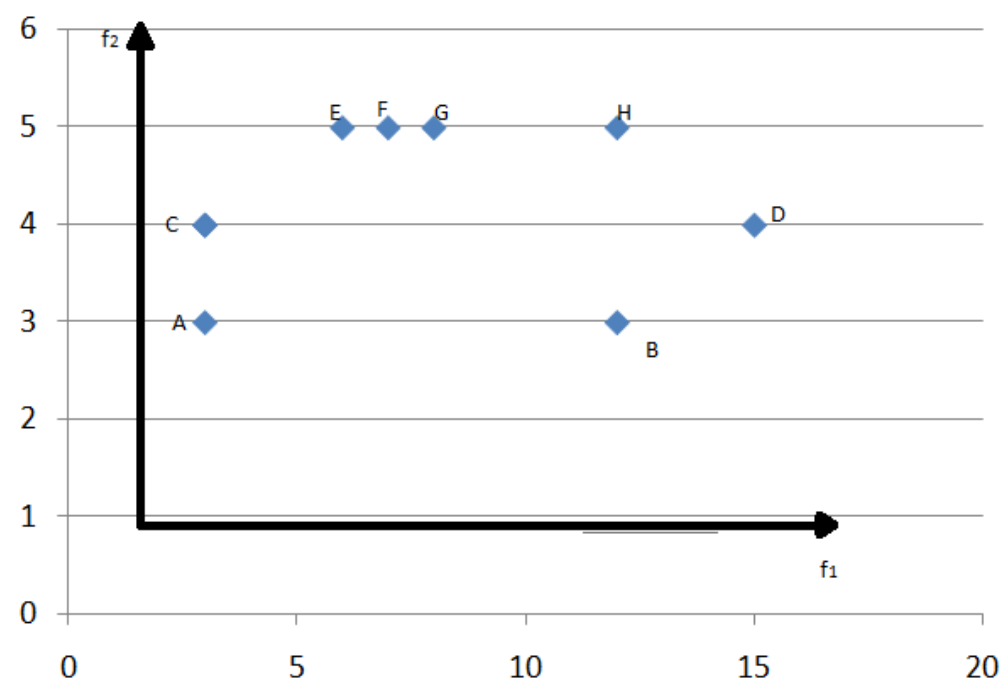

Figure 2. Représentation des solutions

Let us consider our problem with two objectives:

Let us call the prime objective $f_{1}$ corresponding to the costs of assignment and the second $f_{2}$ corresponding to levels of incompetence. For this problem, one finds a whole of solutions corresponding to the weights. The two objectives are to be minimized. This set of solutions is represented in the following table:

\begin{tabular}{|l|l|l|l|l|l|l|l|l|}
\hline & A & B & C & D & E & F & G & H \\
\hline A & & $(+,=)$ & $(=,+)$ & $(+,+)$ & $(+,+)$ & $(+,+)$ & $(+,+)$ & $(+,+)$ \\
\hline B & & & $(-,+)$ & $(+,+)$ & $(-,+)$ & $(-,+)$ & $(-,+)$ & $(=,+)$ \\
\hline C & & $(+,-)$ & & $(+,=)$ & $(+,+)$ & $(+,+)$ & $(+,+)$ & $(+,+)$ \\
\hline D & & & & & $(-,+)$ & $(-,+)$ & $(-,+)$ & $(-,+)$ \\
\hline E & & & & $(+,-)$ & & $(+,=)$ & $(+,=)$ & $(+,=)$ \\
\hline F & & & & & & & $(+,=)$ & $(+,=)$ \\
\hline G & & & & & & & & $(+,=)$ \\
\hline H & & & & & & & & \\
\hline
\end{tabular}

\section{Set of potentially efficient solutions by level}

Applying this method on this group of dots makes it possible to release the set of efficient solutions of first level.

$$
\begin{gathered}
E_{1}(P)=\{(3,3)\} \\
E_{2}(P)=\{(3,4),(12,3)\} \\
E_{3}(P)=\{(15,4),(6,5)\} \\
E_{4}(P)=\{(7,5)\} \\
E_{5}(P)=\{(8,5)\} \\
E_{6}(P)=\{(12,5)\}
\end{gathered}
$$

\section{Probably efficient assignments}

Assignments are built by starting with elements of first level efficient solutions set to elements of the last level efficient solutions set.

However, it is possible to even accept an assignment in the last level set of efficient solutions with an aim of the intensification and diversification in research because filtration will come to decide between the solutions. What leads to:

$$
\begin{array}{cc}
C_{3,3}^{\prime}-S_{1} ; C_{2,2}^{\prime}-S_{2} ; C_{1,1}^{\prime}-S_{3} & I(9,11) \\
C_{3,3}^{\prime}-S_{1} ; C_{2,2}^{\prime}-S_{3} ; C_{1,1}^{\prime}-S_{2} & J(16,13) \\
C_{2,2}^{\prime}-S_{2} ; C_{3,3}^{\prime}-S_{3} ; C_{1,1}^{\prime}-S_{1} & K(23,14)
\end{array}
$$




$$
\begin{aligned}
& C_{2,2}^{\prime}-S_{1} ; C_{3,3}^{\prime}-S_{2} ; C_{1,1}^{\prime}-S_{3} \quad L(30,11) \\
& C_{2,2}^{\prime}-S_{1} ; C_{1,1}^{\prime}-S_{2} ; C_{3,3}^{\prime}-S_{3} \quad M(27,13) \\
& C_{3,3}^{\prime}-S_{2} ; C_{2,2}^{\prime}-S_{3} ; C_{1,1}^{\prime}-S_{1} \quad N(33,14)
\end{aligned}
$$

Let us apply the EDAS to filter assignments:

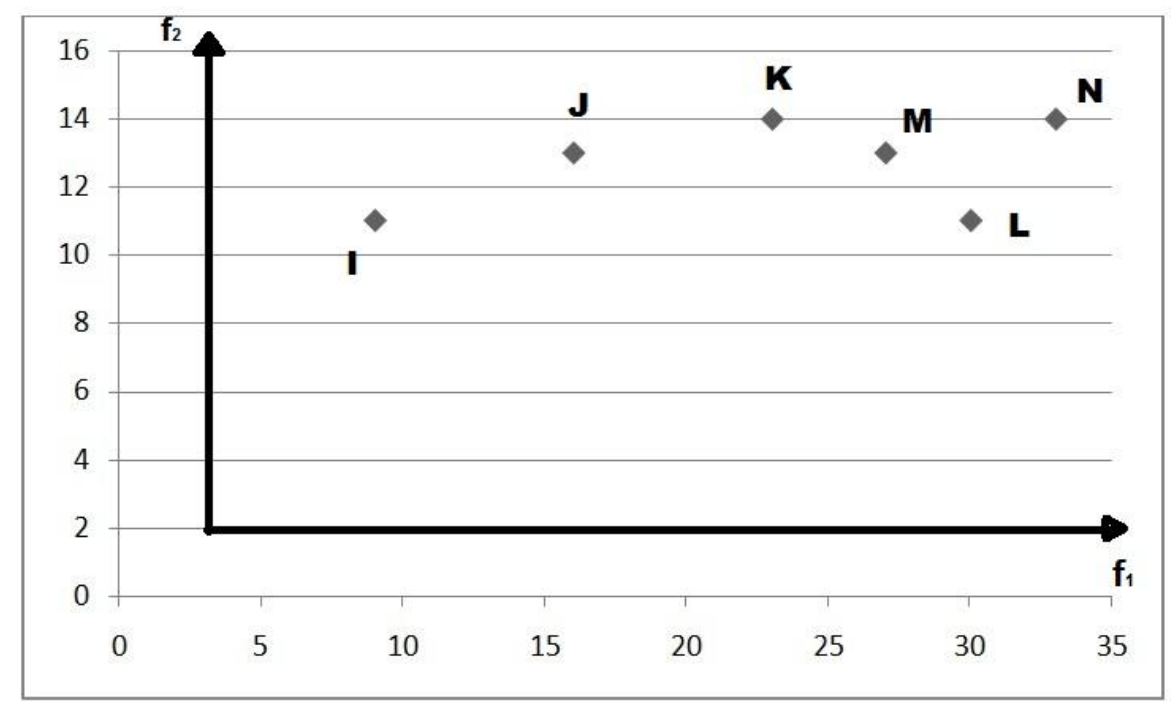

Figure 3. Efficient solutions 1

$$
E(P)=\{(9,11)\}
$$

Corresponding to the assignment: $C_{3,3}^{\prime}-S_{1} ; C_{2,2}^{\prime}-S_{2} ; C_{1,1}^{\prime}-S_{3}$

Table 6. Matrix I of cloud of points (2)

\begin{tabular}{|c|c|c|c|}
\hline & $S_{1}$ & $S_{2}$ & $S_{3}$ \\
\hline$C_{1,2}$, & $(11,4)$ & $(5,3)$ & $(4,6)$ \\
\hline$C_{2,3}$, & $(9,4)$ & $(9,3)$ & $(7,3)$ \\
\hline$C_{3,1}$, & $(7,3)$ & $(11,7)$ & $(6,5)$ \\
\hline
\end{tabular}

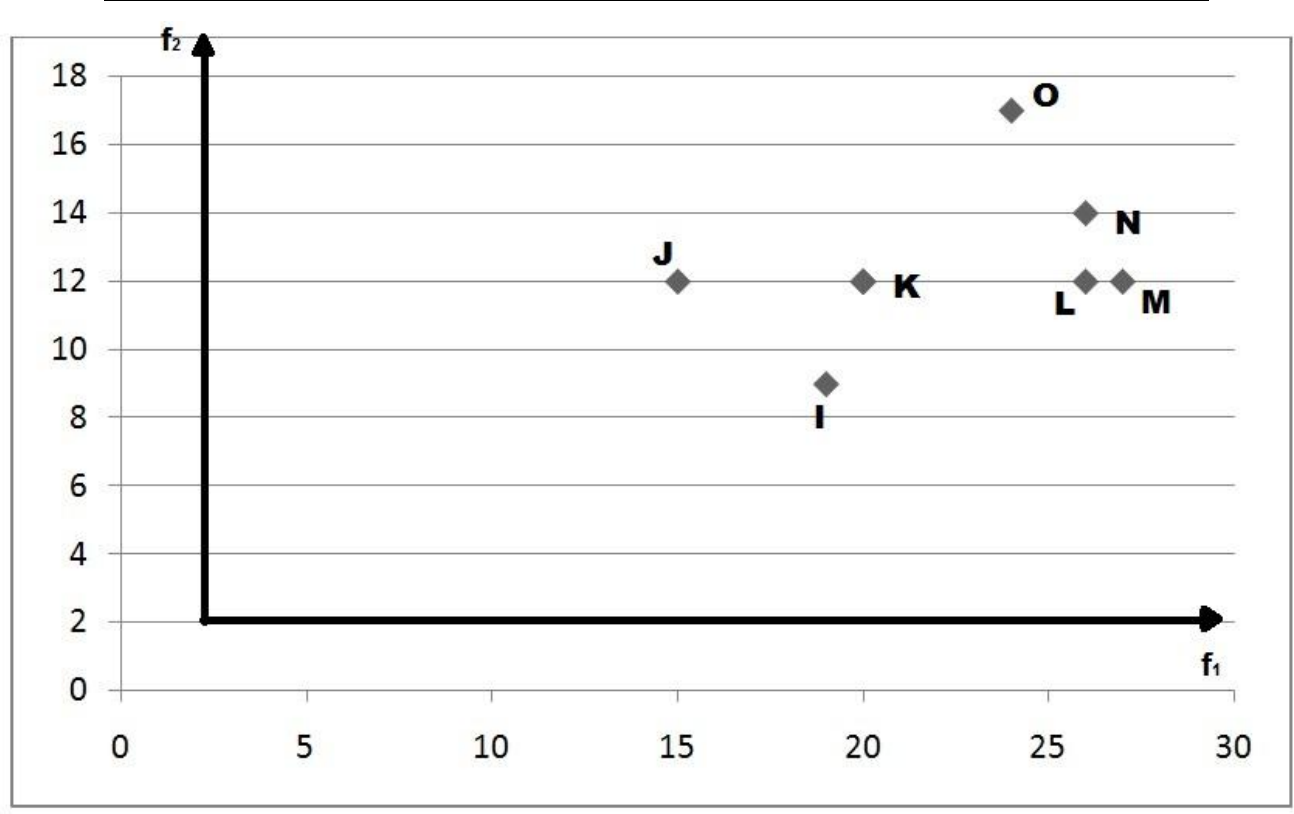

Figure 4. Efficient solutions 2

\section{Set of potentially efficient solutions by level}

Application of this method on this cloud of points makes it possible to release the first level set of efficient solutions. Suppressing points of this set and applying anew EDAS on remaining points gives us the second level set of efficient solutions and so on. 


$$
\begin{gathered}
E_{1}(P)=\{(5,3)\} \\
E_{2}(P)=\{(7,3)\} \\
E_{3}(P)=\{(9,3)\} \\
E_{4}(P)=\{(4,6),(6,5),(9,4)\} \\
E_{5}(P)=\{(11,4)\} \\
E_{6}(P)=\{(11,7)\}
\end{gathered}
$$

Probably efficient assignments

$$
\begin{array}{cc}
C_{1,2}^{\prime}-S_{2} ; C_{2,3}^{\prime}-S_{3} ; C_{3,1}^{\prime}-S_{1} & A(19,9) \\
C_{1,2}^{\prime}-S_{2} ; C_{3,1}^{\prime}-S_{3} ; C_{2,3}^{\prime}-S_{1} & B(15,12) \\
C_{1,2}^{\prime}-S_{2} ; C_{2,3}^{\prime}-S_{1} ; C_{3,1}^{\prime}-S_{3} & C(20,12) \\
C_{2,3}^{\prime}-S_{3} ; C_{1,2}^{\prime}-S_{1} ; C_{3,1}^{\prime}-S_{2} & D(26,14) \\
C_{2,3}^{\prime}-S_{2} ; C_{1,2}^{\prime}-S_{3} ; C_{3,1}^{\prime}-S_{1} & E(20,12) \\
C_{2,3}^{\prime}-S_{2} ; C_{3,1}^{\prime}-S_{3} ; C_{1,2}^{\prime}-S_{1} & F(26,12) \\
C_{2,3}^{\prime}-S_{2} ; C_{1,2}^{\prime}-S_{1} ; C_{3,1}^{\prime}-S_{3} & G(27,12) \\
C_{2,1}^{\prime}-S_{2} ; C_{2,3}^{\prime}-S_{1} ; C_{3,1}^{\prime}-S_{2} & H(24,17)
\end{array}
$$

Let us apply EDAS to filter assignments:

$$
E(P)=\{(15,12),(19,9)\}
$$

Corresponding to assignments :

$$
\begin{gathered}
C_{1,2}^{\prime}-S_{2} ; C_{2,3}^{\prime}-S_{3} ; C_{3,1}^{\prime}-S_{1} \quad A(19,9) \\
C_{1,2}^{\prime}-S_{2} ; C_{3,1}^{\prime}-S_{3} ; C_{2,3}^{\prime}-S_{1} \quad B(15,12)
\end{gathered}
$$

Table 7. Matrix I of cloud of points (3)

\begin{tabular}{|c|c|c|c|}
\hline & $S_{1}$ & $S_{2}$ & $S_{3}$ \\
\hline$C_{1,3}$ & $(8,5)$ & $(11,2)$ & $(5,4)$ \\
\hline$C_{2,1}$, & $(13,4)$ & $(5,6)$ & $(5,3)$ \\
\hline$C_{3,2}$, & $(6,2)$ & $(9,5)$ & $(7,7)$ \\
\hline
\end{tabular}

Set of potentially efficient solutions by level

$$
\begin{gathered}
E_{1}(P)=\{(6,2),(5,3)\} \\
E_{2}(P)=\{(5,4),(11,2)\} \\
E_{3}(P)=\{(13,4),(8,5),(5,6)\} \\
E_{4}(P)=\{(9,5)\} \\
E_{5}(P)=\{(7,7)\}
\end{gathered}
$$

Probably efficient assignment

$$
\begin{array}{ll}
C_{3,2}^{\prime}-S_{1} ; C_{2,1}^{\prime}-S_{3} ; C_{1,3}^{\prime}-S_{2} & A(22,7) \\
C_{3,2}^{\prime}-S_{1} ; C_{1,3}^{\prime}-S_{3} ; C_{2,1}^{\prime}-S_{2} & B(16,12) \\
C_{2,1}^{\prime}-S_{3} ; C_{1,3}^{\prime}-S_{1} ; C_{3,2}^{\prime}-S_{2} & C(22,13) \\
C_{1,3}^{\prime}-S_{3} ; C_{2,1}^{\prime}-S_{1} ; C_{3,2}^{\prime}-S_{2} & D(27,13)
\end{array}
$$

Let us apply EDAS to filter assignments:

$$
E(P)=\{(22,7),(16,12)\}
$$

Corresponding to assignments: 


$$
\begin{aligned}
& C_{3,2}^{\prime}-S_{1} ; C_{2,1}^{\prime}-S_{3} ; C_{1,3}^{\prime}-S_{2} \\
& C_{3,2}^{\prime}-S_{1} ; C_{1,3}^{\prime}-S_{3} ; C_{2,1}^{\prime}-S_{2}
\end{aligned}
$$

By doing the same, we install other matrices of clouds and apply EDAS in order to find other sets of efficient solutions.

\subsection{Results and Discussion}

The obtained sets of efficient solutions union for the six sub-problems is:

$$
E(P)=\{(13,9),(12,15),(9,11),(15,12),(19,9),(22,7),(16,12),(18,9),(15,11),(24,10)\}
$$

The filtration of all these alternatives gives us the set of the efficient solutions for the studied problem:

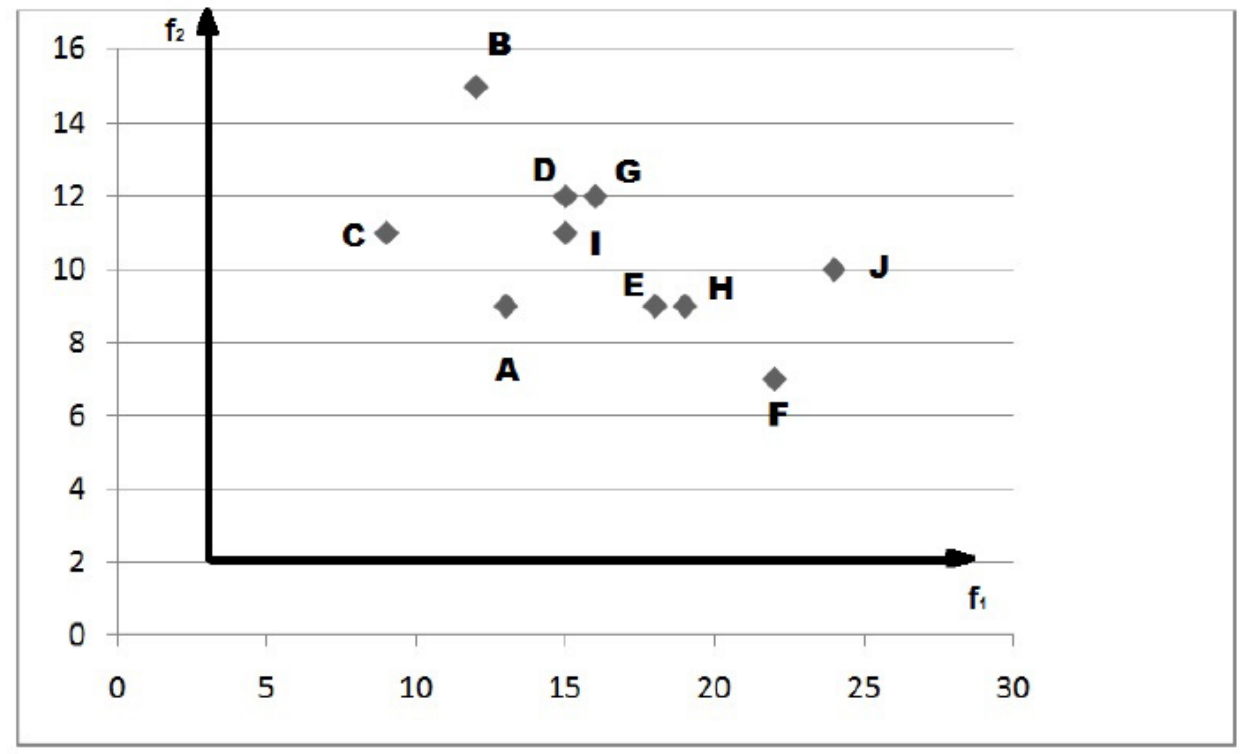

Figure 5. Efficient solutions 7

These solutions correspond respectively to the following assignments:

$$
C_{3,3}^{\prime}-S_{1} ; C_{2,2}^{\prime}-S_{2} ; C_{1,1}^{\prime}-S_{3} \& C_{3,3}^{\prime}-S_{1} ; C_{2,1}^{\prime}-S_{3} ; C_{1,2}^{\prime}-S_{2} \& C_{3,2}^{\prime}-S_{1} ; C_{2,1}^{\prime}-S_{3} ; C_{1,3}^{\prime}-S_{2}
$$

\section{CONClusion}

In this description, the number of sector is constant. Then, criteria would have to be modified because there are sectors havingtheir responsibilities higherthan the peak capacity that a controller can manage. The constraint of equity which makes it possible to preserve the free competition of airline companies prevents us from using traditional methods of traffic assignment on the networks at cost of nonseparable arcs and induces a strong complexity obliging us to direct itself towards the methods of multicriteria optimization. After having developed our method as well as the applications adapted to air traffic problems, we realize that the set up algorithm deals with air traffic problems in an effective way and makes it possible to obtain the same results as by the Method of Preferential Reference of Dominance applied in [2].

\section{REFERENCES}

[1] Collette, Y. and Siarry, P. Optimisationmultiobjectif. Eyrolles, Paris 2002.

[2] Kikomba, M., Ngoie, R.-B. M., Mabela, R. and Makengo, F. Simultaneous Optimization: Sectorization and congolese air traffic assignment by the method of preferential reference of dominance. International Journal of Scientific and Innovative Mathematical research 4(2) : 2941, February 2016.

[3] Okitonyumbe, J., Ulungu, B. Some, K., Kapiamba, J. and Ilunga, A. Dominance Preferential Reference Mark Method with Adapted Clark and Wright Heuristic to solve Multi-Objective Vehicle Routing Problem. International Journal of Current Advaced Research 4(10) : 454-460, October 2015. 


\section{AUTHORS' BIOGRAPHY}

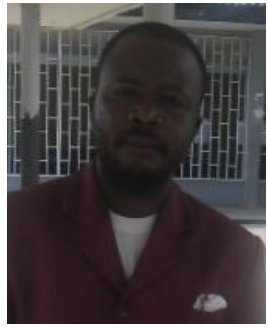

Michaël KIKOMBA KAHUNGU, is senior lecturer at InstitutSupérieur des Techniques Appliquées de Kasangulu (Applied Enginneering College of Kasangulu), Kongo Central, DR Congo. He teaches Mathematics for engineers and Statistics.

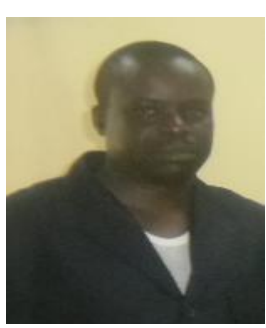

Rostin MABELA MAKENGO MATENDO, is Professor at University of Kinshasa (UNIKIN). He teaches Probability Calculus, Operations Research, Data Analysis and Mathematical Statistics.

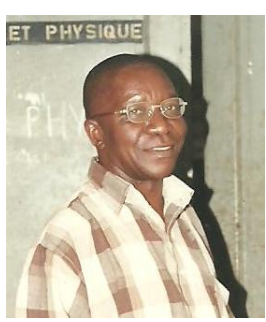

Donatien NTANTU IBULA, is Professor at UniversitéPédagogiqueNationale, Democratic Republic of the Congo. He teaches Functional Analysis, Digital Topology, Graphs Theory and Algebraic Topology. 